\title{
Accurate Load Modeling Based on Analytic Hierarchy Process
}

\author{
Zhenshu Wang, ${ }^{1}$ Xiaohui Jiang, ${ }^{1}$ Shaorun Bian, ${ }^{2}$ Yangyang $\mathrm{Ma}^{1}$ and Bowen Fan ${ }^{1}$ \\ ${ }^{1}$ Key Laboratory of Power System Intelligent Dispatch and Control of Ministry of Education, Shandong University, Jinan 250061, China \\ ${ }^{2}$ Jinan Power Supply Company of National Grid, Jinan 250100, China
}

Correspondence should be addressed to Zhenshu Wang; zhenshuwang@sdu.edu.cn

Received 27 October 2015; Revised 16 February 2016; Accepted 18 February 2016

Academic Editor: George S. Tombras

Copyright (C) 2016 Zhenshu Wang et al. This is an open access article distributed under the Creative Commons Attribution License, which permits unrestricted use, distribution, and reproduction in any medium, provided the original work is properly cited.

\begin{abstract}
Establishing an accurate load model is a critical problem in power system modeling. That has significant meaning in power system digital simulation and dynamic security analysis. The synthesis load model (SLM) considers the impact of power distribution network and compensation capacitor, while randomness of power load is more precisely described by traction power system load model (TPSLM). On the basis of these two load models, a load modeling method that combines synthesis load with traction power load is proposed in this paper. This method uses analytic hierarchy process (AHP) to interact with two load models. Weight coefficients of two models can be calculated after formulating criteria and judgment matrixes and then establishing a synthesis model by weight coefficients. The effectiveness of the proposed method was examined through simulation. The results show that accurate load modeling based on AHP can effectively improve the accuracy of load model and prove the validity of this method.
\end{abstract}

\section{Introduction}

The main models of power system include generator, power line, and load models. Compared with generator models and power line models, load models have lower accuracy. With the scale of power grid expanding and center of power load increasing, load model will have more and more significant meaning in power system digital simulation and dynamic security analysis $[1-5]$.

In the development of power system, lots of load modeling methods have been proposed, mainly including component-based modeling approach $[6,7]$, measurementbased modeling approach $[8,9]$, and fault-based modeling approach [10]. Measurement-based modeling approach considers the power load as a whole. Parameters of load model can be identified by voltage, frequency, current, and phase angle data of acquiring bus of field devices and experiment. It is a simple and practical way to solve load modeling problems. Load characteristic data are important factor affecting load model results [11].

Power distribution network impedance and reactive power compensation are not considered in traditional composite load models. To overcome this problem, the synthesis load model (SLM) that considers the impact of power distribution network and compensation capacitor is built in [12-14]. The SLM overcomes the deficiencies of traditional composite load model. It can easily simulate motor load, static load, distribution network, and compensation capacitor in power system. However, the randomness characteristics of load power cannot be described precisely.

With the rapid development of electrified railway, proportion of electrified railway traction load in power load is increasing every year. Electric locomotive, the main composition of traction power system, is a high-power rectifier load. It has significant impact on power system security and stability [15]. Electric traction load has an uncertain interference degree to power system at different times [16, 17]. Dynamic equations and simulation models of traction motor circuit are deduced in $[18,19]$. The SLM considers the impact of power distribution network impedance and compensation capacitor, while randomness of power load is well described by traction power system load model (TPSLM).

Single load model cannot describe power load accurately and effectively. The accurate load modeling based on analytic hierarchy process (AHP) is proposed in this paper. To analyze qualitative problems quantitatively, internal connections and differences of these two models are used as criteria of AHP. Weight coefficients of these two models can be calculated, 


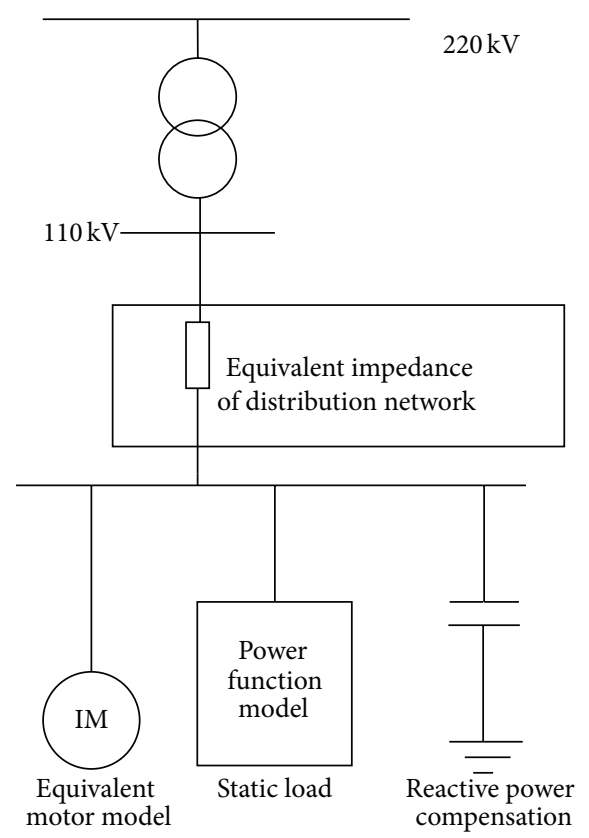

FIgURE 1: The structure diagram of SLM.

after different criteria hierarchies are formed by analyzing internal connections and differences. Distribution network and traction power system synthesis load model will establish after synthesizing these two load models by weight coefficients.

\section{Distribution Network and Traction Power System Synthesis Load Model}

2.1. The SLM. The SLM is proposed in [12, 13], which include equivalent static load, equivalent motor load, distribution network, and compensation capacitor. The SLM structure is shown in Figure 1.

Ignoring the influence of frequency variation, threeorder electromechanical transient model is used to describe equivalent motor model:

$$
\begin{aligned}
T_{d 0}^{\prime} \frac{d E_{d}^{\prime}}{d t} & =-E_{d}^{\prime}-\left(X-X^{\prime}\right) I_{q}+s \omega_{B} E_{q}^{\prime} T_{d 0}^{\prime}, \\
T_{d 0}^{\prime} \frac{d E_{q}^{\prime}}{d t} & =-E_{q}^{\prime}+\left(X-X^{\prime}\right) I_{d}-s \omega_{B} E_{d}^{\prime} T_{d 0}^{\prime}, \\
T_{j} \frac{d s}{d t} & =T_{m}-T_{e}, \\
I_{d} & =\frac{1}{R_{s}^{2}+X^{\prime 2}}\left[R_{s}\left(U_{l d}-E_{d}^{\prime}\right)+X^{\prime}\left(U_{l q}-E_{q}^{\prime}\right)\right], \\
I_{q} & =\frac{1}{R_{s}^{2}+X^{\prime 2}}\left[R_{s}\left(U_{l q}-E_{q}^{\prime}\right)-X^{\prime}\left(U_{l d}-E_{d}^{\prime}\right)\right], \\
P_{i m} & =U_{d} I_{d}+U_{q} I_{q}, \\
Q_{i m} & =U_{q} I_{d}-U_{d} I_{q},
\end{aligned}
$$

where $E_{d}^{\prime}, E_{q}^{\prime}$ are the $d$-axis and $q$-axis motor transient electromotive force in the synchronous rotating coordinate system; $U_{l d}, U_{l q}$ are the $d$-axis and $q$-axis bus voltage, while $I_{d}, I_{q}$ represent the $d$-axis and the $q$-axis stator currents; $s$ is the rotor slip of motor; $\omega_{B}$ is the electrical angular frequency base value; mechanical torque $T_{m}=K_{L}\left[\alpha+(1-\alpha)(1-s)^{p}\right]$; electromagnetic torque $T_{e}=E_{d}^{\prime} I_{d}+E_{q}^{\prime} I_{q}$; the motor load rate coefficient $K_{L}=P_{M 0}^{*} /\left(\alpha+(1-\alpha)\left(1-s_{0}\right)^{P}\right) ; \alpha$ is the coefficient of drag torque that has no relationship with rotate speed; $T_{j}$ is the rotor inertia time constant; $X^{\prime}=X_{s}+X_{m} X_{r} /\left(X_{m}+\right.$ $X_{r}$ ) is the rotor transient reactance; $X=X_{s}+X_{m}$ is the steady rotor reactance; $R_{s}$ is the stator resistance; $R_{r}$ is the rotor resistance; $X_{s}$ is the stator reactance; $X_{r}$ is the rotor reactance; $X_{m}$ is the mutual inductance reactance; $T_{d 0}^{\prime}=$ $\left(X_{r}+X_{m}\right) / R_{r}$ is the rotor circuit time constant; the parameter $P_{M 0}$ is used to define the initial active power proportion of the equivalent motor in the composite load model; $P_{\mathrm{im}}, Q_{\mathrm{im}}$ are the active power and reactive power of equivalent induction motor model.

The power function model is used to describe static load in Figure 1:

$$
\begin{aligned}
P_{s} & =P_{s 0}\left(\frac{U}{U_{0}}\right)^{n_{p}}, \\
Q_{s} & =Q_{s 0}\left(\frac{U}{U_{0}}\right)^{n_{q}},
\end{aligned}
$$

where $P_{s}, Q_{s}$, and $U$ are the active power, reactive power, and load bus voltage magnitude of actual equivalent static load; $P_{s 0}, Q_{s 0}$, and $U_{0}$ are the active power, reactive power, and load bus voltage magnitude of reference point operated stably; $n_{p}, n_{q}$ are the active voltage and reactive voltage feature coefficients, respectively.

The capacitance compensation model is used to describe the reactive power compensation in Figure 1:

$$
Q_{c}=-\frac{U^{2}}{X_{c}}=-\frac{U^{2}}{X_{c 0}} f
$$

in which $Q_{c}$ is reactive power from the grid; $f$ represents frequency of power system; $X_{c}$ is compensation reactance; $X_{c 0}$ is compensation capacitor.

To sum up, power balances of SLM in bus bars are

$$
\begin{aligned}
P_{1} & =P_{d}+P_{s}+P_{\mathrm{im}}, \\
Q_{1} & =Q_{d}+Q_{s}+Q_{\mathrm{im}}-Q_{c}
\end{aligned}
$$

in which $P_{1}, Q_{1}$ are the active power and reactive power of SLM; $P_{d}, Q_{d}$ are the active power and reactive power of distribution network; $P_{s}, Q_{s}$ are the active power and reactive power of static load; $P_{\mathrm{im}}, Q_{\mathrm{im}}$ are the active power and reactive power of equivalent induction motor model, respectively; $Q_{c}$ is the reactive power of compensation capacitor.

2.2. The TPSLM. The TPSLM mainly includes traction power supply networks and traction trains. Traction train loads include traction motor, locomotive auxiliary load, and carriage load. The locomotive traction power supply is single 


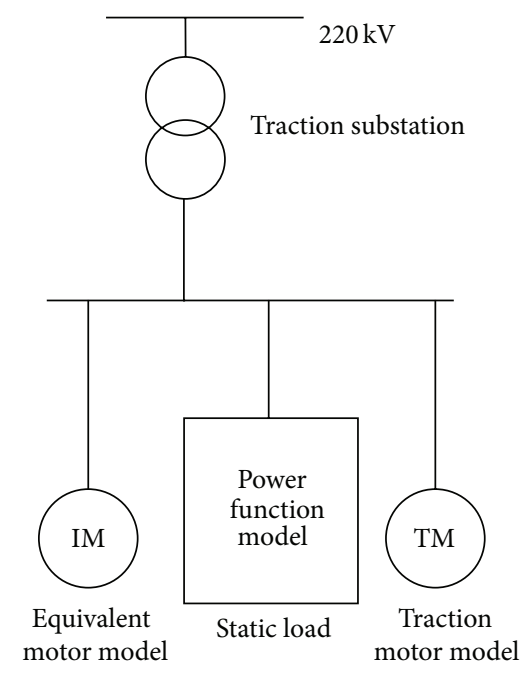

FIGURE 2: The structure diagram of TPSLM.

phase alternating current, in which the traction motor is supplied by the locomotive rectifier, which belongs to the single phase load. The induction motor in the auxiliary unit of the locomotive is powered by the splitter, which is a threephase load. Carriage load includes air conditioning, electric water heater, and a little proportion of light load [20, 21].

According to the research on the structure and load characteristics of traction power supply system, the load model of traction power supply system with "induction motor parallel traction motor and constant impedance" is proposed in [20]. The TPSLM structure is shown in Figure 2.

In Figure 2, static load model uses the power function model; induction motor load model uses the three-order electromechanical transient model.

Expressions of traction motor load model are as follows:

$$
\begin{aligned}
L \frac{d I_{d}}{d t} & =U_{\mathrm{tm}}-R I_{d}-C_{e} K_{s} \omega I_{d} \\
J \frac{d \omega}{d t} & =C_{T} K_{s} \omega I_{d}^{2}-T_{L}, \\
P_{\mathrm{tm}} & =U_{\mathrm{tm}} I_{d},
\end{aligned}
$$

where $I_{d} \omega$ are the current and rotating speed of equivalent traction motor; $L, R$ are the inductance and resistance of traction motor loop; $J, K_{s}$ are the rotary inertia and excitation coefficient of traction motor; $U_{\mathrm{tm}}$ is traction substation voltage; considering $C_{T}=C_{e} K_{s}, C_{e}$ and $C_{T}$ are the voltage coefficient and torque coefficient of traction motor; the mechanical load torque $T_{L}$ has influence on the mechanical properties of traction motor. The operating mode switch of electric locomotive is frequent. According to [20], $T_{L}=$ $T_{L 0}\left(A \omega^{2}+B \omega+C\right)$; considering $A+B+C=1 ; T_{L 0}$ is the traction motor load rate.

To sum up, power balances of TPSLM in bus bars are

$$
\begin{aligned}
& P_{2}=P_{s}+P_{\mathrm{tm}}+P_{\mathrm{im}} \\
& Q_{2}=Q_{s}+Q_{\mathrm{im}},
\end{aligned}
$$

where $P_{2}, Q_{2}$ are the active power and reactive power of the traction power system load model; $P_{s}, Q_{s}$ are the active power and reactive power of static load; $P_{\mathrm{im}}, Q_{\mathrm{im}}$ are the active power and reactive power of equivalent induction motor model; $P_{\mathrm{tm}}$ is the active power of traction motor model.

\subsection{Distribution Network and Traction Power System Synthesis} Load Model Structure. The SLM considers the impact of power distribution network and compensation capacitor, while randomness of power load is more precisely considered by TPSLM. The distribution network and traction power system synthesis load model (DTSLM) interacts with SLM and TPSLM; its structure is shown in Figure 3.

The SLM uses system capacity as a reference value which is three-phase bus-bar voltage, while TPSLM is more complex.

Traction substation is supplied by power grid and the voltage is $110 \mathrm{kV}$ typically. Contact net, which is supply by traction power system, connects traction substation. The voltage of contact net is mainly $25 \mathrm{kV}$. Voltage bases of TPSLM and SLM are not consistent. Voltage reference of SLM is bus-bar side, while the equivalent traction motor model and induction motor model are based on traction side. Equivalent "system transformation" is essential:

$$
\begin{aligned}
& U_{\mathrm{tm}}=K_{\mathrm{vt}} U \\
& U_{\mathrm{im}}=K_{\mathrm{vi}} U
\end{aligned}
$$

where $K_{\mathrm{vt}}$ is the transform coefficient between traction motor voltage and bus voltage, $K_{\mathrm{vi}}$ is the transform coefficient between induction motor voltage and bus voltage; $U_{\mathrm{tm}}, U_{\mathrm{im}}$ are traction motor voltage and induction motor voltage under voltage base of the traction power system load model; $U$ is root mean square of system voltage.

To sum up, power balances of DTSLM in bus-bar are

$$
\begin{aligned}
& P=P_{1}+P_{2}, \\
& Q=Q_{1}+Q_{2}
\end{aligned}
$$

in which $P, Q$ are the active power and reactive power of DTSLM; $P_{1}, Q_{1}$ are the active power and reactive power of SLM; $P_{2}, Q_{2}$ are the active power and reactive power of TPSLM, respectively.

\section{The AHP}

The AHP is a scientific decision-making method in system engineering, which has been proposed by Satty in the 1970s [22]. It is an effective method to solve multiobjective and multilevel decision-making problems; weight coefficients can be calculated by digitizing some factors. However, the AHP is difficult to quantitative analysis completely [23].

Power plant site selection and integrated resource planning evaluation are considered by a lot of influence factors, such as social, technical, and operation in [24-27]. In [17, 28], a method based on AHP is proposed to improve power quality evaluation system and analyze high-speed rail major impacts on power supply grid. Compared with traditional 


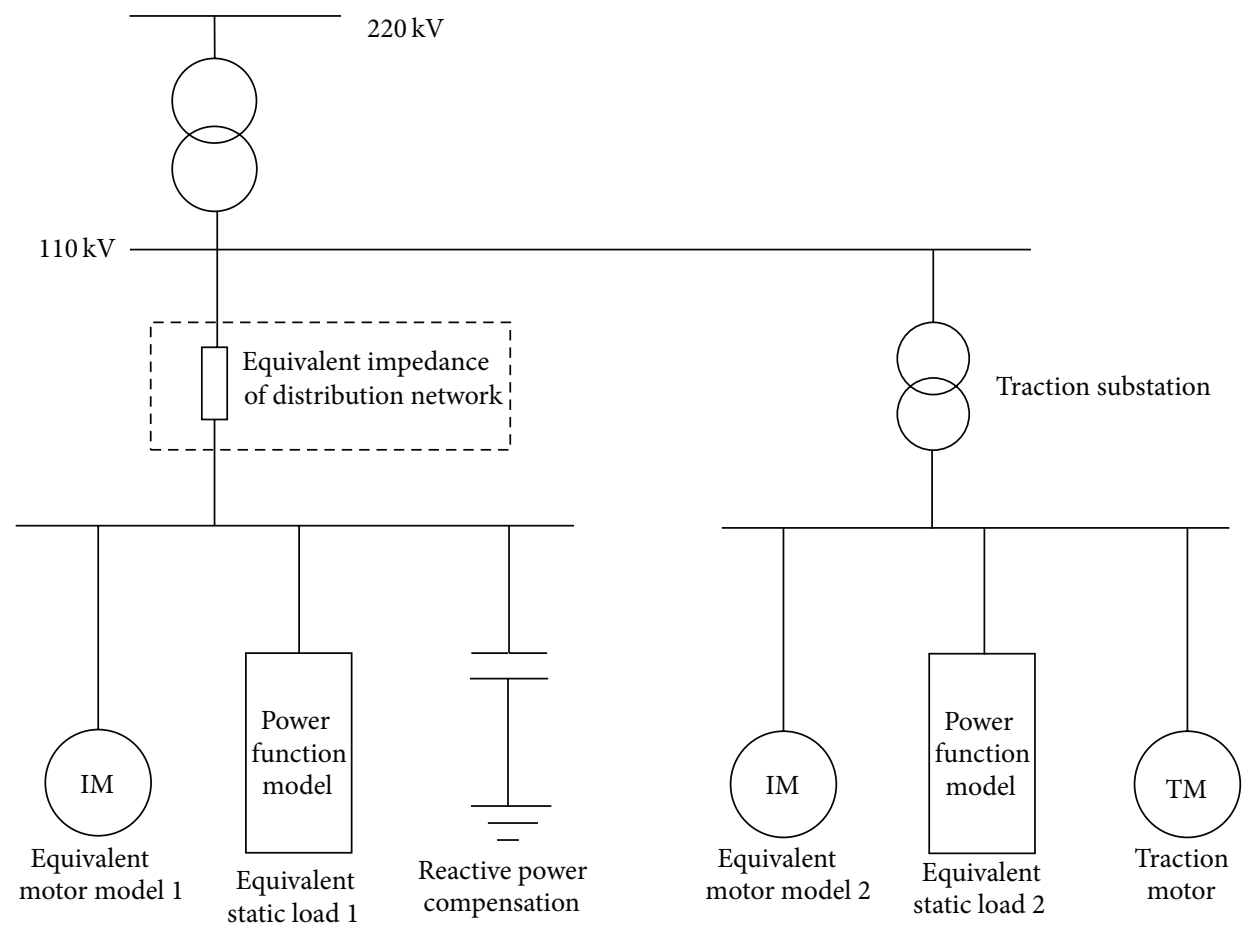

FIgURE 3: The structure diagram of DTSLM.

TABLE 1: Comparison scale.

\begin{tabular}{ll}
\hline $\begin{array}{l}\text { Numerical } \\
\text { scale }\end{array}$ & Verbal scale \\
\hline 1 & $\begin{array}{l}\text { Element } i \text { has equal importance as element } j \\
\text { Element } i \text { is moderately important compared to } \\
\text { element } j \\
\text { Element } i \text { is strongly important compared to } \\
\text { element } j\end{array}$ \\
7 & $\begin{array}{l}\text { Element } i \text { is very strongly important compared to } \\
\text { element } j\end{array}$ \\
9 & $\begin{array}{l}\text { Element } i \text { is extremely important compared to } \\
\text { element } j\end{array}$ \\
$2,4,6$, and 8 & \begin{tabular}{l} 
Intermediate value between adjacent scale values \\
\hline
\end{tabular}
\end{tabular}

decision-making methods, influences of qualitative factors are fully considered in AHP. The AHP decomposes factors of objective hierarchy into several levels. To analyze the problem synthetically, human experiences and judgments are integrated in criteria hierarchy. It has solved problems of quantitative information and lack of flexibility. The "1-9 scale method," as shown in Table 1, is combined with expert judgment to form a judgment matrix. Quantify results are obtained by simple mathematical calculation. It is scientific way to optimize complex mathematical models and circumvent heavy computation demands of traditional decisionmaking methods.

The main procedure of AHP can be divided into four steps:
(1) Structure the decision hierarchy from top with the objective hierarchy to bottom with the scheme hierarchy. Objective hierarchy divides decision-making factors into several categories to be the criteria hierarchy. Issues of affiliation form a top-down relationship.

(2) Form judgment matrix using the "1-9 scale method." The core of the AHP is forming judgment matrix using integers and reciprocal between 1 and 9. Weight coefficients of each hierarchy can be calculated by judgment matrix.

(3) Test consistency of judgment matrix.

(4) Calculate weight coefficient of scheme hierarchy under the standard of criteria hierarchy layer by layer.

\section{Accurate Load Modeling Based on AHP}

4.1. Established AHP Structure. The main idea of the AHP is to establish a hierarchical model based on the decisionmaking problem, which is divided into three levels, namely, the objective hierarchy, the criterion hierarchy, and the scheme hierarchy. The establishment of the hierarchical structure of the graph is shown in Figure 4.

\subsection{Judgment Matrix of Criteria Hierarchy}

(1) Objective Hierarchy. Including one goal, the expected results for the problem or the ideal goal, the goal of modeling load is to accurately characterize the load characteristics.

(2) Criteria Hierarchy. Including four evaluation criteria, active power fitting degree, reactive power fitting degree, 


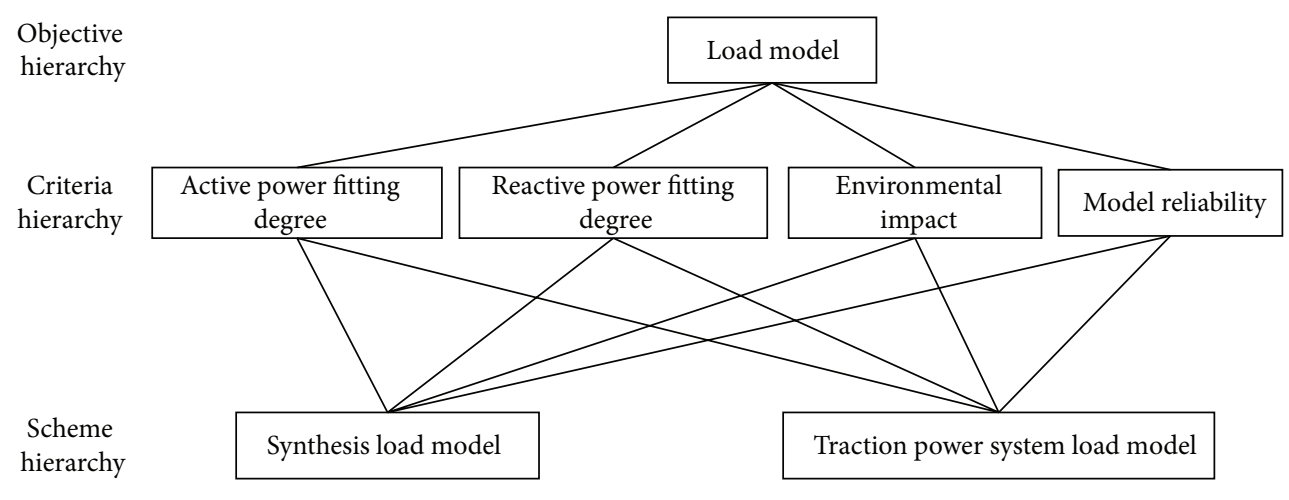

FIGURE 4: Hierarchy model structure of AHP.

TABLE 2: Criteria hierarchy judgment matrix.

\begin{tabular}{lcccc}
\hline$a_{i j}$ & $A$ & $R$ & $E$ & $M$ \\
\hline$A$ & $a_{11}$ & $a_{12}$ & $a_{13}$ & $a_{14}$ \\
$R$ & $a_{21}$ & $a_{22}$ & $a_{23}$ & $a_{24}$ \\
$E$ & $a_{31}$ & $a_{32}$ & $a_{33}$ & $a_{34}$ \\
$M$ & $a_{41}$ & $a_{42}$ & $a_{43}$ & $a_{44}$ \\
\hline
\end{tabular}

$A$ is active power fitting degree; $R$ is reactive power fitting degree; $E$ is environmental impact; $M$ is model reliability.

environmental impact, and model reliability. Considering the importance of four criteria, active power fitting degree and reactive power fitting degree, which can describe the accuracy and rationality of the load model precisely, are more important than the other two criteria. With the change of season, climate, and living habit, the composition of power load will also change, which can reflect the randomness of power load. Model reliability is credibility of these two models. According to accuracy, scaling factor in the judgment matrix can be set. Criteria hierarchy judgment matrix is shown in Table 2. $a_{i j}$ is a comparison between scheme $i$ and scheme $j$; symmetry element $a_{j i}$ is a comparison between scheme $j$ and scheme $i$; diagonal element $a_{i i}$ is a comparison between scheme $i$ and itself, and its value is equal to 1 apparently.

(3) Scheme Hierarchy. It includes two kinds of load models, respectively, considering the SLM and TPSLM. The SLM can accurately simulate distribution network and reactive power compensation system, while randomness of power system can be described by TPSLM.

\subsection{Judgment Matrix of Each Criterion}

(1) Active Power Fitting Degree. On the basis of measured data or test data, model parameters can be identified by measurement-based modeling approach. Calculate active power fitting degree based on obtained difference between measured values and calculated values of load model. Judgment matrix can be formed by standards of the "1-9 scale method." As the real-time data of the field acquisition
TABLE 3: Judgment matrix of each criterion.

\begin{tabular}{lcc}
\hline$b_{i j}$ & SLM & TPSLM \\
\hline SLM & $b_{11}$ & $b_{12}$ \\
TPSLM & $b_{21}$ & $b_{22}$ \\
\hline
\end{tabular}

or experiment is different, the calculated values and the measured values of the model will be changed, so that the composition and size of the actual load of the power system can be reflected in real time and accurately.

(2) Reactive Power Fitting Degree. Implementation steps are similar to that of active power fitting degree. Calculate the reactive power fitting degree based on difference between models measured values and calculated values of load model and form judgment matrix of reactive power fitting degree.

(3) Environmental Impact. The power load has characteristics that are uncertain and time-varying. With the change of season, climate and living habit, the composition of power load will also change. Electrified railway is widely used in modern railway transportation. That has increased the proportion of traction load in power system. Considering environment factors, the SLM cannot describe randomness of power load precisely, so the TPSLM accounts for a larger proportion.

(4) Model Reliability. The model reliability is not only a subjective judgment of identification results, but also an improvement of existing models. Judgment matrix of SLM and TPSLM in criteria hierarchy is formed by literature and experience. In [29], sensitivity of traction load model under voltage disturbances is higher than that of constant impedance model, while it is lower than that of the induction motor model. So SLM accounts for a larger proportion considering model reliability factors.

Judgment matrix of each criterion is shown in Table 3.

Judgment matrix of active power fitting degree and reactive power fitting degree will be calculated after identifying parameters of SLM and TPSLM. 
4.4. Parameter Identification of Single Load Model. From (1) to (4), a total of 15 independent parameters of the SLM need to be identified:

$$
\begin{aligned}
& \theta_{1}=\left[R_{D}, X_{D}, s_{0}, T_{d 0}^{\prime}, R_{s}, X_{s}, R_{r}, X_{r}, T_{j}, a, P, n_{p}, n_{q}, X_{C 0},\right. \\
& \left.P_{M P}\right] .
\end{aligned}
$$

According to $[30,31]$, the sensitivity of parameters $\left[T_{d 0}^{\prime}, R_{s}, R_{r}, X_{r}, T_{j}, a, P\right]$ is low, and these parameters use the typical values:

$$
\begin{aligned}
T_{d 0}^{\prime} & =0.576, \\
R_{s} & =0, \\
R_{r} & =0.02, \\
X_{r} & =0.12, \\
T_{j} & =2, \\
\alpha & =0.15, \\
P & =2 .
\end{aligned}
$$

To sum up, 8 parameters in SLM need to be identified:

$$
\theta_{1}^{\prime}=\left[R_{D}, X_{D}, s_{0}, X_{s}, n_{p}, n_{q}, X_{C 0}, P_{M P}\right] .
$$

From (5) to (6), it can be seen that 21 parameters in TPSLM need to be identified:

$$
\begin{gathered}
\theta_{2}=\left[s_{0}, T_{d 0}^{\prime}, R_{s}, X_{s}, R_{r}, X_{r}, T_{j}, a, P, n_{p}, n_{q}, K_{\mathrm{vt}}, K_{\mathrm{vi}}, K_{\mathrm{tm}},\right. \\
\left.K_{\mathrm{im}}, R, C_{T}, L, J, A, B\right]
\end{gathered}
$$

where $K_{\mathrm{tm}}, K_{\mathrm{im}}$ are the proportion of the traction and induction motor initial active power, respectively. Equivalent load random fluctuation caused by natural factors uniform for mechanical traction motor load torque changes in $[13,14]$. $T_{L}$ is traction motor load torque, considering $A=0.5$, $B=0.3$, and $C=0.2 ; T_{L}=T_{L 0}\left(A \omega^{2}+B \omega+C\right)=$ $T_{L 0}\left(0.5 \omega^{2}+0.3 \omega+0.2\right)$. Induction motor and reactive power compensation parameters reference the typical values in [30, 31].

The objective function of measurement-based modeling approach is

$$
\min \varepsilon(\theta)=\min \frac{1}{n} \sum_{k=1}^{n}\left[\left(P_{c}-P_{m}\right)^{2}+\left(Q_{c}-Q_{m}\right)^{2}\right]
$$

in which $P_{c}, Q_{c}$ are the active power and reactive power of measurement; $P_{m}, Q_{m}$ are the calculated power of load model. $n$ is number of samples. When the difference between the calculated values of the load model and the measured values of the simulation is in a certain error range, parameters of the load model are identified.

In [32], load model is evaluated by relative error in the following formula:

$$
\varepsilon=100 \times \frac{\left((1 / N) \sum_{k=1}^{N}(y(k)-\widehat{y}(k))^{2}\right)^{1 / 2}}{\left((1 / N) \sum_{k=1}^{N} y(k)^{2}\right)^{1 / 2}},
$$

where $N$ is the number of samples; $y(k), \hat{y}(k)$ are the measured power of simulation and calculated power of load models. If relative error is less than $5 \%$, this load model is considered to be acceptable.

4.5. Calculated Weight Coefficients of Judgment Matrix. There are four ways to calculate weight coefficients of judgment matrix which are geometric average method, arithmetic average method, feature vector method, and least square method. Feature vector method is the most common way to calculate weight coefficients, which has advantage of simple calculation process and high calculating speed. That uses judgment matrix normalized eigenvectors of maximum characteristic root as weight coefficients. Feature vector method is used to calculated weight coefficients of judgment matrix in this paper.

Feature vector method uses weight coefficients $\omega$ to revise multiply judgment matrix $A$ :

$$
A \omega=\lambda_{\max } \omega
$$

in which $\lambda_{\max }$ is the maximum characteristic root; the positive $\omega$ as eigenvectors of maximum characteristic root is the only one; weight coefficients of analytic hierarchy process will be calculation after normalizing eigenvectors.

The criteria hierarchy weight coefficient is $\omega_{0}, \omega_{1}, \omega_{2}$ are weight coefficient of active power fitting and reactive power fitting degree, and $\omega_{3}, \omega_{4}$ are weight coefficient of environmental impact and model reliability, respectively.

The final weight coefficients of load models are as follows:

$$
\omega=\left[\left(\omega_{1}, \omega_{2}, \omega_{3}, \omega_{4}\right) \cdot \omega_{0}\right]^{T} .
$$

To sum up, flow diagram of accurate load modeling based on AHP is shown in Figure 5.

\section{Simulation Example}

To illustrate load modeling based on AHP that can effectively improve the accuracy of load model, a simulation based on Matlab/Simulink is carried out in this paper. Locomotive auxiliary load and carriage load, which is equal to threephase induction motor in parallel power function model, are connected to high voltage side of traction transformer. The faults are chosen as three-phase short circuit with the duration of $0.04 \mathrm{~s}$. The simulation system is depicted in Figure 6; as for the system parameters, one can refer to [33].

Load modeling data must be the responses of voltage, current, active power, and reactive power. Data of SLM, TPSLM, and DTSLM under the disturbance occurring outside the region can be measured from simulation system in Figure 6, which are measured values of load characteristic. Model parameters and values of fitting curves of load models are calculated by parameter identification. According to parameter identification results, judgment matrixes and weight coefficients are calculated. The validity and effectiveness of the method can be illustrated by analyzing the test results.

Parameters identification of SLM results is shown in Table 4. Power fitting curves of SLM are shown in Figures 7(a) and 7(b). 


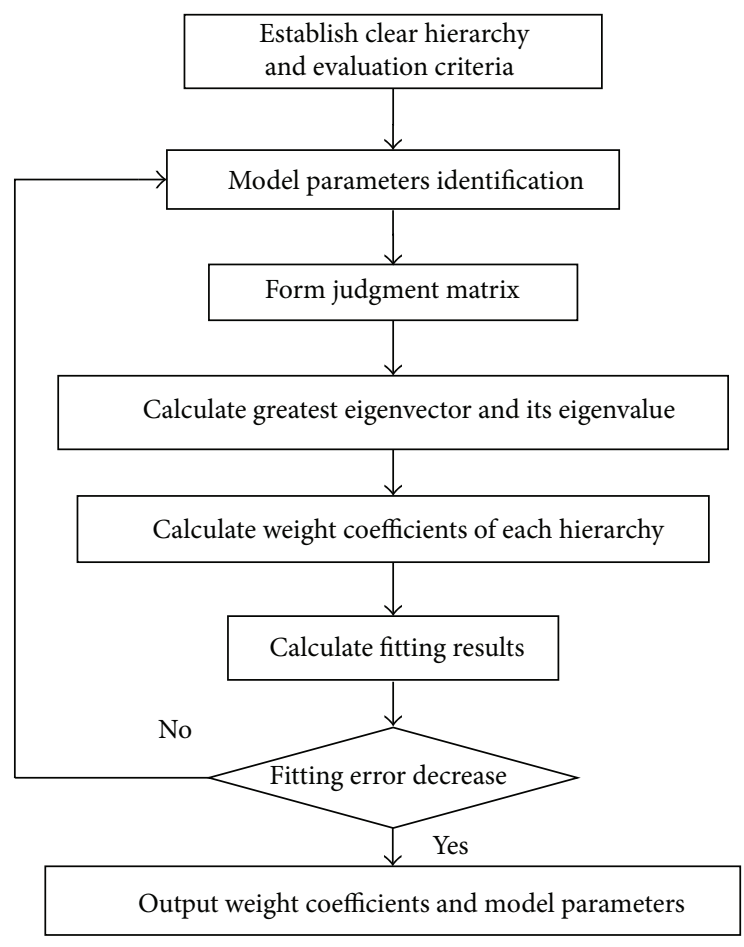

Figure 5: Flow diagram of load modeling based on AHP.

TABLE 4: Parameter of SLM.

\begin{tabular}{lccc}
\hline$P_{M P}$ & 0.3179 & $k_{D}$ & 1.8799 \\
$X_{s}$ & 0.3357 & $X_{D}$ & 0.0817 \\
$s_{0}$ & 0.0177 & $n_{p}$ & 2.1976 \\
$X_{C 0}$ & 1.7748 & $n_{q}$ & 1.8346 \\
$\varepsilon_{p}(\%)$ & 0.39 & $\varepsilon_{q}(\%)$ & 0.68 \\
\hline
\end{tabular}

TABLE 5: Parameter of TPSLM.

\begin{tabular}{lccc}
\hline$K_{\mathrm{vt}}$ & 0.3089 & $K_{\mathrm{vi}}$ & 0.9985 \\
$K_{\mathrm{tm}}$ & 0.7872 & $K_{\mathrm{im}}$ & 0.0998 \\
$X_{s}$ & 0.1736 & $s_{0}$ & 0.0162 \\
$n_{p}$ & 1.2499 & $n_{q}$ & 1.5658 \\
$R_{s}$ & 0.1319 & $X_{r}$ & 0.1852 \\
$J$ & 6.7924 & $R$ & 0.0423 \\
$L$ & 5.9969 & $C_{T}$ & 3.0074 \\
$\varepsilon_{p}(\%)$ & 1.08 & $\varepsilon_{q}(\%)$ & 0.42 \\
\hline
\end{tabular}

Under the circumstance that model parameters identification result is reasonable, the average error of active power, reactive power, and total error is $6.9308 \times 10^{-5}, 9.9626 \times$ $10^{-5}$, and $1.5893 \times 10^{-4}$, respectively. Relative error is less than $5 \%$. Within the error rang allowed, model fitting is relatively accurate.

Parameters identification results of TPSLM are shown in Table 5. Power fitting curves of TPSLM are shown in Figures $8(\mathrm{a})$ and $8(\mathrm{~b})$.

Under the circumstance that model parameters identification result is reasonable, the average error of active power,
TABLE 6: The criteria hierarchy judgment matrix.

\begin{tabular}{lcccc}
\hline$a_{i j}$ & $A$ & $R$ & $E$ & $M$ \\
\hline$A$ & 1 & 1 & 4 & 5 \\
$R$ & 1 & 1 & 4 & 5 \\
$E$ & $1 / 4$ & $1 / 4$ & 1 & 2 \\
$M$ & $1 / 5$ & $1 / 5$ & $1 / 2$ & 1 \\
\hline
\end{tabular}

$A$ is active power fitting degree; $R$ is reactive power fitting degree; $E$ is environmental impact; $M$ is model reliability.

TABLE 7: Judgment matrix of active power fitting degree.

\begin{tabular}{lcc}
\hline$a_{i j}$ & SLM & TPSLM \\
\hline SLM & 1 & 5 \\
TPSLM & $1 / 5$ & 1 \\
\hline
\end{tabular}

TABLE 8: Judgment matrix of reactive power fitting degree.

\begin{tabular}{lcc}
\hline$a_{i j}$ & SLM & TPSLM \\
\hline SLM & 1 & $1 / 2$ \\
TPSLM & 2 & 1 \\
\hline
\end{tabular}

TABLE 9: Judgment matrix of environmental impact.

\begin{tabular}{lcc}
\hline$a_{i j}$ & SLM & TPSLM \\
\hline SLM & 1 & $1 / 5$ \\
TPSLM & 5 & 1 \\
\hline
\end{tabular}

TABLE 10: Judgment matrix of model reliability.

\begin{tabular}{lcc}
\hline$a_{i j}$ & SLM & TPSLM \\
\hline SLM & 1 & 3 \\
TPSLM & $1 / 3$ & 1 \\
\hline
\end{tabular}

reactive power, and total error is $8.7753 \times 10^{-5}, 1.3880 \times 10^{-4}$, and $2.2655 \times 10^{-4}$, respectively. Relative error is less than $5 \%$. Within the error rang allowed, TPSLM considers more randomness of power load.

According to the relationship between models, judgment matrix of criteria hierarchy can be calculated, which is shown in Table 6. After load model parameters identification, judgment matrixes of each criterion can be calculated, which are shown in Tables 7, 8, 9, and 10.

Final weight coefficients are calculated by feature vector method. The criteria hierarchy weight coefficient $\omega_{0}=$ $[0.4061,0.4061,0.1151,0.0727]^{T}$; weight coefficient of active power fitting degree $\omega_{1}=[0.8333,0.1667]^{T}$; weight coefficient of reactive power fitting degree $\omega_{2}=[0.3333,0.6667]^{T}$; weight coefficient of environmental impact $\omega_{3}=[0.1667$, $0.8333]^{T}$; weight coefficient of model reliability $\omega_{4}=[0.7500$, $0.2500]^{T}$. 


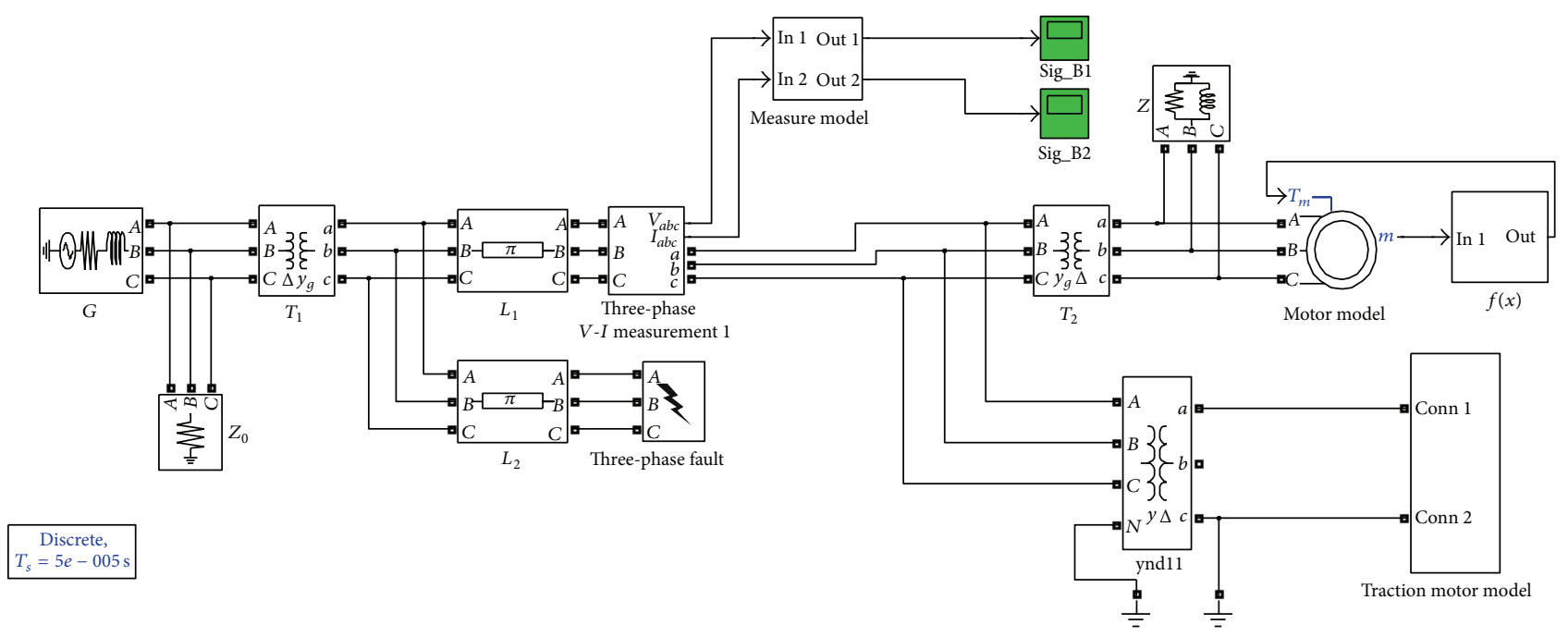

FIgURE 6: Load modeling based on AHP simulation system in Matlab/Simulink.

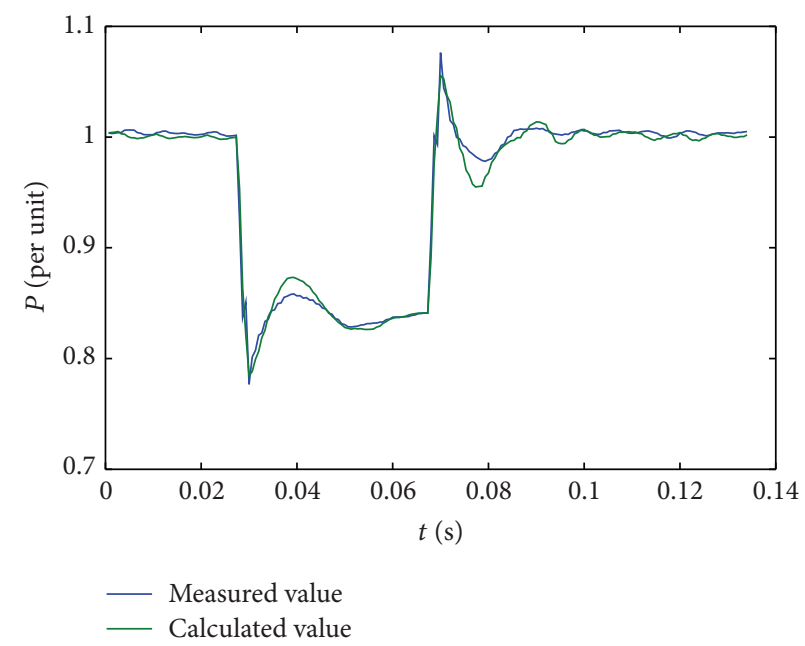

(a)

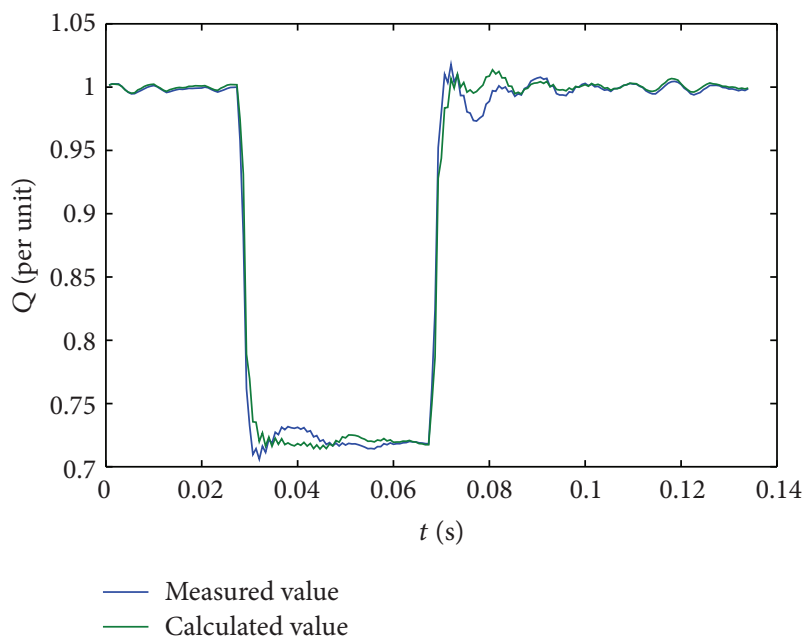

(b)

Figure 7: Power fitting curves of SLM.

The final weight coefficients of load models are as follows:

$\omega=\left[\left(\omega_{1}, \omega_{2}, \omega_{3}, \omega_{4}\right) \cdot \omega_{0}\right]^{T}$

$$
\begin{aligned}
& =\left[\begin{array}{llll}
0.8333 & 0.3333 & 0.1667 & 0.7500 \\
0.1667 & 0.6667 & 0.8333 & 0.2500
\end{array}\right]\left[\begin{array}{l}
0.4061 \\
0.4061 \\
0.1151 \\
0.0727
\end{array}\right] \\
& =[0.5475,0.4525]^{T},
\end{aligned}
$$

where $\omega$ are weight coefficients of each model in accurate load modeling based on AHP. The final load model will be calculated by weighting SLM and TPSLM.
Power fitting curves of accurate load model based on AHP are shown in Figures 9(a) and 9(b).

Comparison of average error is shown in Table 11. From model identification parameters of Tables 4 and 5, it indicates that the accurate load modeling based on AHP can decrease error obviously under reasonable model parameters and weight coefficients. From power fitting curves of load models in Figures 7, 8, and 9, the accurate load modeling based on AHP can fit measured values and calculated values more precisely. Simulation results prove that $54.75 \%$ of SLM and $45.25 \%$ of TPSLM could accurately describe the characterization of load model at this moment.

\section{Conclusion}

The method of accurate load modeling based on AHP is proposed in this paper. On the basis of SLM, TPSLM, which 
TABLE 11: Comparison of average error.

\begin{tabular}{lccc}
\hline Model error & Active power error & Reactive power error & Total error \\
\hline SLM & $6.9308 \times 10^{-5}$ & $9.9626 \times 10^{-5}$ & $1.5893 \times 10^{-4}$ \\
TPSLM & $1.3880 \times 10^{-4}$ & $8.7753 \times 10^{-5}$ & $2.2655 \times 10^{-4}$ \\
DTSLM & $3.9884 \times 10^{-5}$ & $5.9118 \times 10^{-5}$ & $9.9002 \times 10^{-5}$ \\
\hline
\end{tabular}

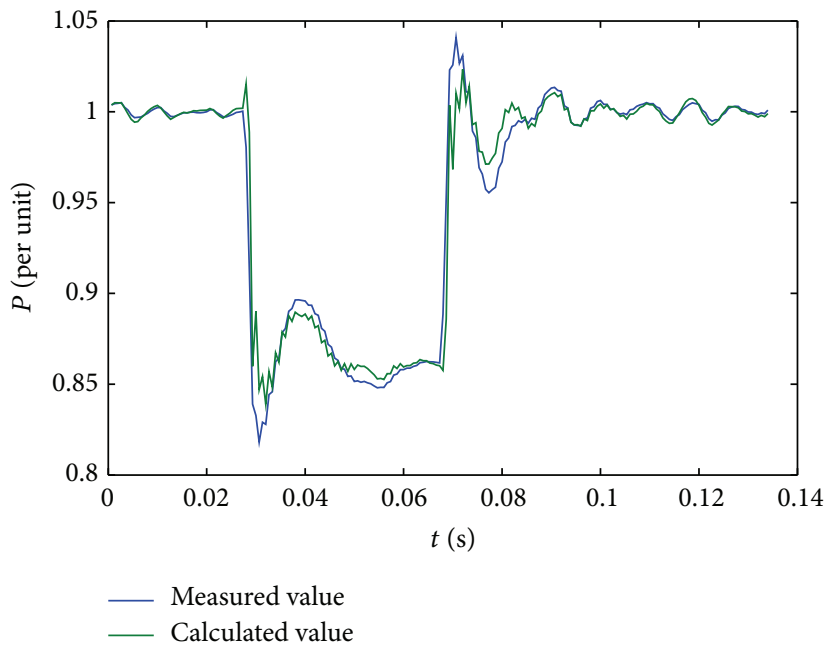

(a)

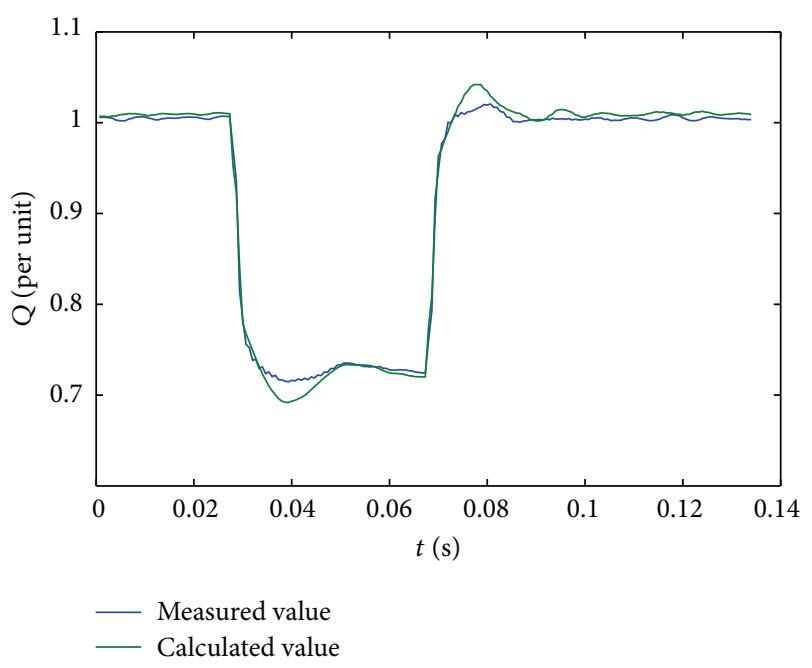

(b)

Figure 8: Power fitting curves of TPSLM.

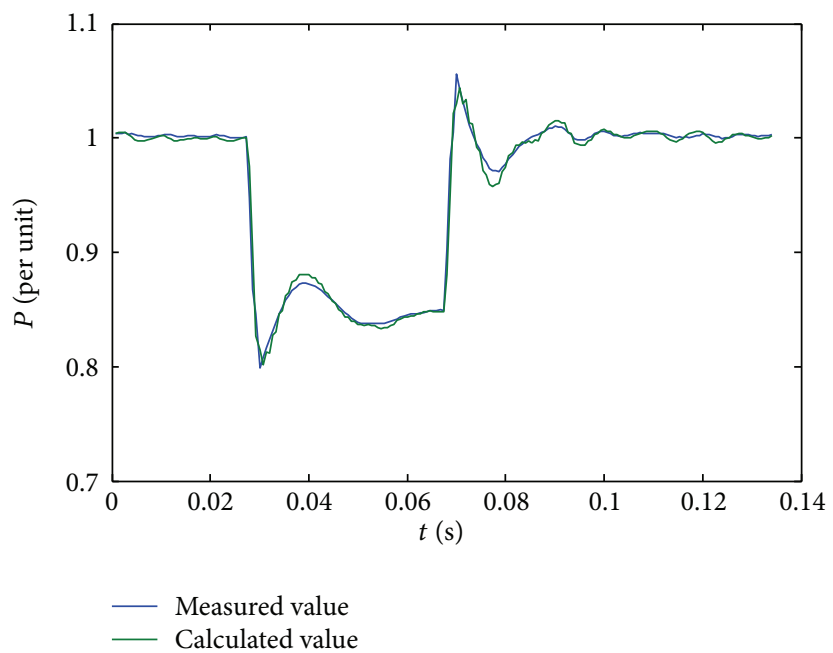

(a)

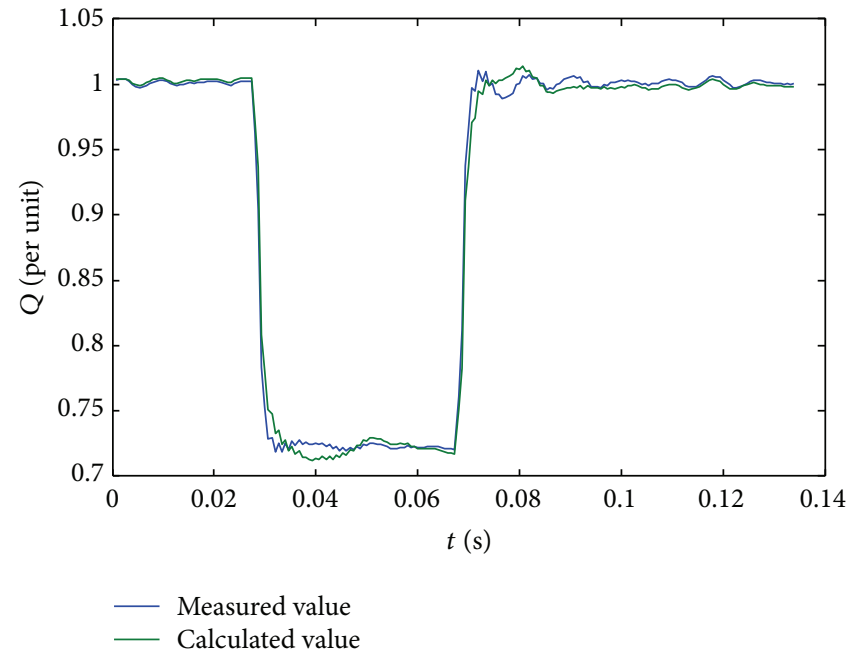

(b)

FIGURE 9: Power fitting curves of accurate load model based on AHP.

considers the randomness of power load, is fused by AHP. This method can adjust the weight coefficients with the change of power load, so the randomness problem of power load can be solved. The effectiveness of the proposed method was examined through simulation. Parameter identification results by measurement-based modeling approach show that load modeling based on AHP can effectively improve the accuracy of load model.

\section{Competing Interests}

The authors declare that there are no competing interests regarding the republication of this paper.

\section{Acknowledgments}

This work is supported by the National Natural Science Foundation of China (Grant no. 51377099) and is also supported by 
Shandong Provincial Science and Technology Development Plan (no. 2014GGX101001).

\section{References}

[1] Z. Wang, S. Bian, M. Lei, C. Zhao, Y. Liu, and Z. Zhao, "Feature extraction and classification of load dynamic characteristics based on lifting wavelet packet transform in power system load modeling," International Journal of Electrical Power and Energy Systems, vol. 62, pp. 353-363, 2014.

[2] T. Yong, H. Junxian, and L. Wenzhou, "The modeling of distribution network and var compensator and induction motor in the load model for power system digital simulation," Proceedings of the CSEE, vol. 25, no. 3, pp. 8-12, 2005.

[3] W. Hongbin, D. Ming, L. Shenghu et al., "Probabilistic analysis on influences of generator model and load model on transient stability," Power System Technology, vol. 28, no. 1, pp. 19-21, 2004.

[4] P. Ju, F. Wu, Z.-Y. Shao et al., "Composite load models based on field measurements and their applications in dynamic analysis," IET Generation, Transmission and Distribution, vol. 1, no. 5, pp. 724-730, 2007.

[5] K. E. Wong and M. E. Haque, "Dynamic load modelling of a paper mill for small signal stability studies," IET Generation, Transmission and Distribution, vol. 8, no. 1, pp. 131-141, 2014.

[6] W. W. Price, K. A. Wirgau, A. Murdoch, J. V. Mitsche, E. Vaahedi, and M. El-Kady, "Load modeling for power flow and transient stability computer studies," IEEE Transactions on Power Systems, vol. 3, no. 1, pp. 180-187, 1998.

[7] Z. Wang, S. Bian, Y. Liu, and Z. Liu, "The load characteristics classification and synthesis of substations in large area power grid," International Journal of Electrical Power \& Energy Systems, vol. 48, no. 1, pp. 71-82, 2013.

[8] C.-J. Lin, Y.-T. Chen, C.-Y. Chiou et al., "Dynamic load models in power systems using the measurement approach," IEEE Transactions on Power Systems, vol. 8, no. 1, pp. 309-315, 1993.

[9] Z. Yan, Z. Wen, C. Xiaodong, and L. Yutian, "Real-time optimal voltage control using measurement-based aggregate load model," Electric Power Systems Research, vol. 116, pp. 293-300, 2014.

[10] Y. Tang, H. Zhang, J. Hou, and D. Zhang, "Study on essential principle and methods for load modeling," Power System Technology, vol. 31, no. 4, pp. 1-5, 2007.

[11] P. Ju, C. Qin, F. Wu, H. Xie, and Y. Ning, "Load modeling for wide area power system," International Journal of Electrical Power \& Energy Systems, vol. 33, no. 4, pp. 909-917, 2011.

[12] Y. Tang, H. Zhang, J. Hou, and D. Zhang, "A synthesis load model with distribution network," Power System Technology, vol. 31, no. 5, pp. 34-38, 2007.

[13] Y. Tang, H.-B. Zhang, D.-X. Zhang, and J.-X. Hou, "A synthesis load model with distribution network for power transmission system simulation and its validation," in Proceedings of the IEEE Power \& Energy Society General Meeting (PES '09), pp. 1-7, IEEE, Calgary, Canada, July 2009.

[14] Y. Zhang, R. Chen, Y. Xiao, W. Zhao, X. Li, and G. Zhang, "Measurement-based modeling of traction power supply system," in Proceedings of the International Conference on Advanced Power System Automation and Protection (APAP '11), pp. 946950, Beijing, China, October 2011.
[15] Z.-H. Lu, J.-W. Li, and J. Zhou, "The impact of electrified railway on electric power system," Relay, vol. 32, no. 11, pp. 33-36, 2004.

[16] G.-D. Zhang, X.-R. Li, and P.-Q. Li, "Simulation research on load characteristics of electric locomotive traction motor," Electric Drive for Locomotives, vol. 1, pp. 21-24, 2009.

[17] J. Bai, W. Gu, X. Yuan, Q. Li, B. Chen, and X. Wang, "Power quality warning of high-speed rail based on multi-features similarity," Journal of Electrical Engineering and Technology, vol. 10, no. 1, pp. 92-101, 2015.

[18] J. Chen, J. Zhu, and Y. Guo, "Modeling and performance analysis of energy regeneration system in electric vehicle with permanent magnet DC motor driving system," in Proceedings of the International Conference on Electrical Machines and Systems (ICEMS '07), pp. 2051-2056, Seoul, South Korea, October 2007.

[19] Y.-C. Liang and V. J. Gosbell, "DC machine models for SPICE2 simulation," IEEE Transactions on Power Electronics, vol. 5, no. 1, pp. 16-20, 1990.

[20] X. Li, G. Zhang, X. Zhu, Z. Hu, and H. Hu, "A load model of traction power supply system," Automation of Electric Power Systems, vol. 33, no. 16, pp. 71-95, 2009.

[21] L. Monjo, L. Sainz, and J. Rull, "Statistical study of resonance in AC traction systems equipped with Steinmetz circuit," Electric Power Systems Research, vol. 103, pp. 223-232, 2013.

[22] T. L. Saaty, "Decision making with the analytic hierarchy process," International Journal of Services Sciences, vol. 1, no. 1, pp. 83-98, 2008.

[23] T. L. Saaty, The Analytic Hierarchy Process, McGraw-Hill, New York, NY, USA, 1980.

[24] Y.-F. Zhao and J.-F. Chen, "Analytic hierarchy process and its application in power system," Electric Power Automation Equipment, vol. 24, no. 9, pp. 85-87, 2004.

[25] W. Guangsheng, H. Zhaoguang, and W. Pingyang, "Decision support system for thermal power plant siting (SDSS)," in Proceedings of the IEEE Region 10 Conference on Computer, Communication, Control and Power Engineering (TENCON'93), vol. 5, pp. 385-387, Beijing, China, October 1993.

[26] R. R. Clarke, "Validation and legitimation of an analytic hierarchy approach to integrated resource planning for electric utilities," in Proceedings of the 32nd Intersociety Energy Conversion Engineering Conference, vol. 3, pp. 2197-2201, August 1997.

[27] R. R. Clarke, "Choosing an integrated resource plan for electric utilities: an analytic hierarchy approach," in Proceedings of the Intersociety Energy Conversion Engineering Conference, vol. 3, pp. 1592-1597, August 1996.

[28] S. A. Farghal, M. S. Kandil, and A. Elmitwally, "Quantifying electric power quality via fuzzy modelling and analytic hierarchy processing," IEE Proceedings-Generation, Transmission and Distribution, vol. 149, no. 1, pp. 44-49, 2002.

[29] J. Li and X. Li, "Transient stability calculation considering traction load model," Electric Power Automation Equipment, vol. 33, no. 4, pp. 109-113, 2013.

[30] P. Ju and D.-Q. Ma, Load Modeling of Power System, China Electric Power Press, Beijing, China, 2008.

[31] Z. Wang, S. Bian, X. Liu, K. Yu, and Y. Shi, "Research on load model parameter identification based on the CQDPSO algorithm," Transactions of China Electrotechnical Society, vol. 29, no. 12, pp. 211-217, 2014. 
[32] B.-K. Choi, H.-D. Chiang, Y. Li et al., "Measurement-based dynamic load models: derivation, comparison, and validation," IEEE Transactions on Power Systems, vol. 21, no. 3, pp. 12761283, 2006.

[33] Y. Han, J. Zhao, S.-Z. Huang et al., "Dynamic model and computation of probabilistic harmonic currents for type-ss 4 locomotive," Automation of Electric Power Systems, vol. 25, no. 4, pp. 31-36, 2001. 


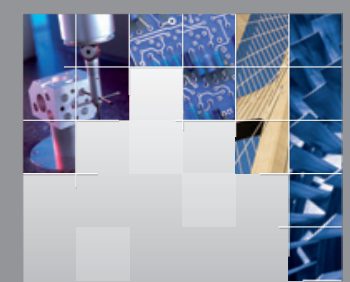

\section{Enfincering}
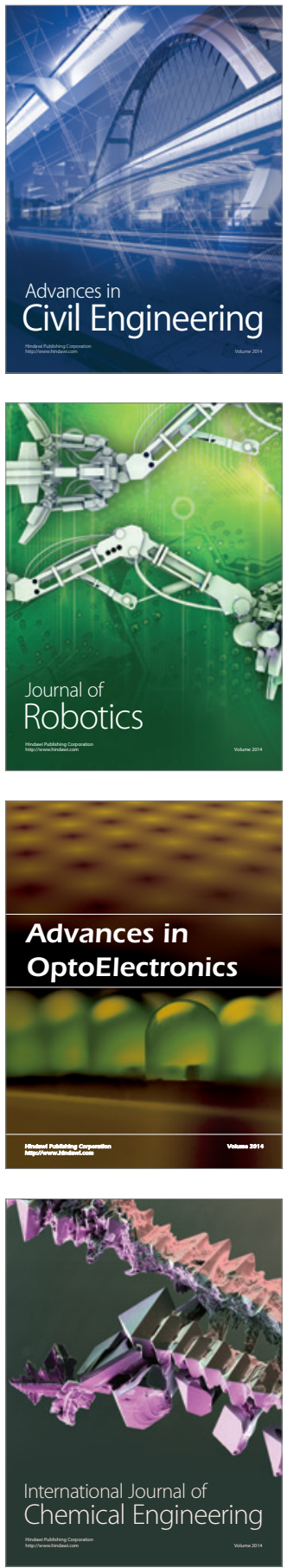

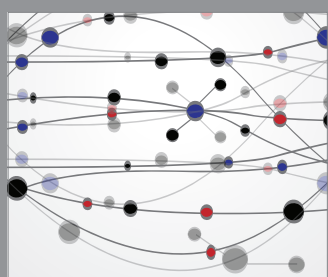

The Scientific World Journal

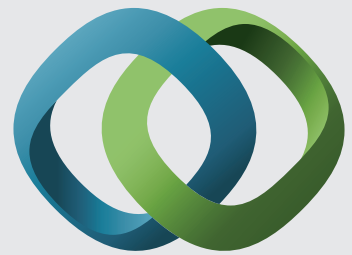

\section{Hindawi}

Submit your manuscripts at

http://www.hindawi.com
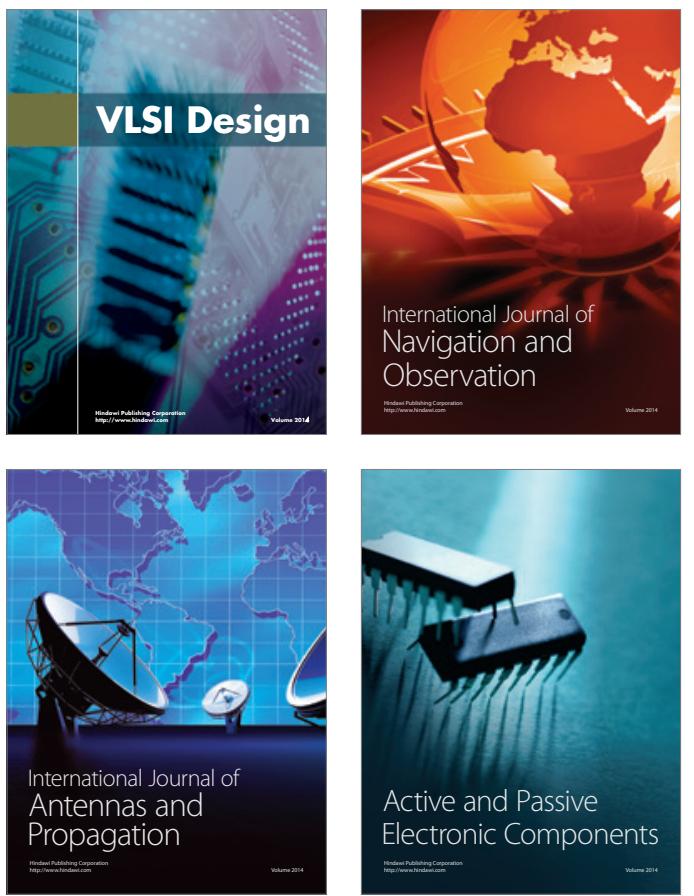
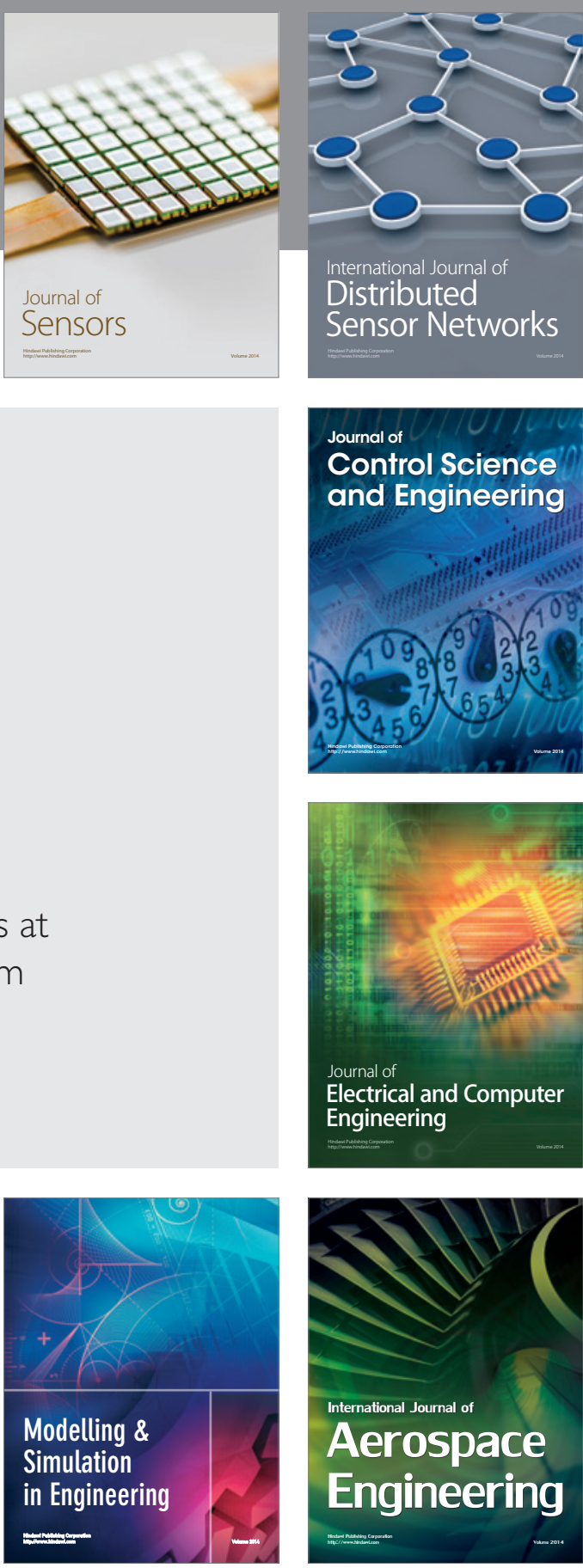

International Journal of

Distributed

Sensor Networks

Journal of

Control Science

and Engineering
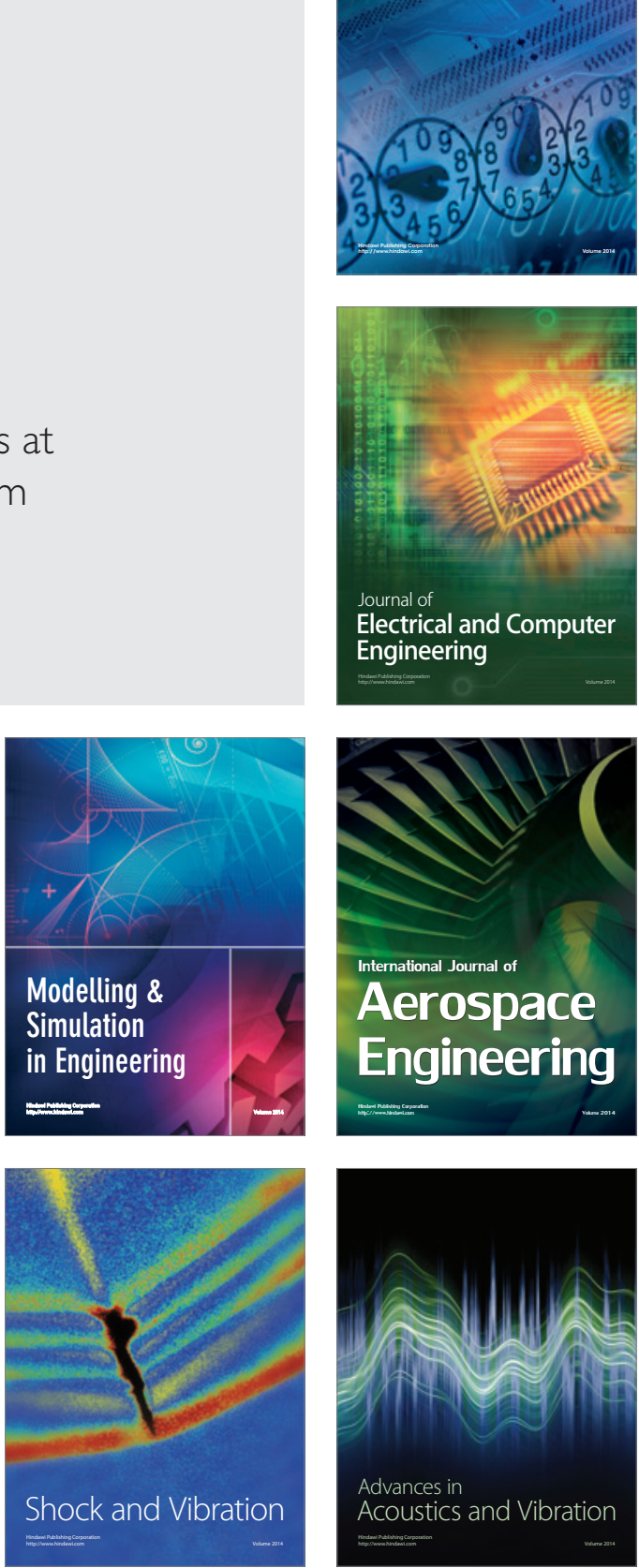